Resumen por el autor, George S. Huntington.

Universidad de Columbia, Nueva York.

La morfología de la arteria pulmonar de los mamíferos.

1. Morfogénesis. El presente trabajo se ocupa de los estados ontogénicos tempranos de la arteria pulmonar en embriones de gato (de 4 a $6 \mathrm{~mm}$.). Las arterias pulmonares de los mamíferos no se originan primariamente como brotes o proliferaciones de los segmentos ventrales del sexto arco aórtico y no se extienden caudalmente por un proceso de crecimiento continuo o "gemación." Se desarrollan por el establecimiento de anastomosis longitudinales entre un cierto número de derivados postbranquiales de las aortas dorsales, que se abren en el esbozo pulmonar, formando un plexo temprano pulmonar postbranquial. Este plexo es al principio completamente independiente del esbozo ventral del sexto arco aórtico, con el cual se reune secundariamente dando lugar, en estados ulteriores, a los brotes que constituyen este vaso y que aparentemente provienen de este arco, como se describe ordinariamente. El esbozo dorsal del sexto arco (conducto de Botal) está constituido por el elemento más cranial del plexo pulmonar postbranquial. 2. Consideraciones filogénicas. Por su significación filogénica los estados ontogénicos tempranos de la arteria pulmonar de los mamíferos colocan a esta arteria en linea serial directa con los canales vasculares respiratorios de los vertebrados inferiores y completan el plan fundamental común a todos los vertebrados para la interpretación de esta porción del sistema vascular hemal. 3. Relación de los estados embrionarios descritos con la aparición de variaciones y mutaciones de la arteria pulmonar en el hombre $\mathrm{y}$ en los vertebrados inferiores. 
AUTHOR'S ARSTRACT OF THIS PAPER ISSUED

BY THE BIBLIOGRAPHIC AERVICE, OCTOBER 27

\title{
THE MORPHOLOGY OF THE PULMONARY ARTERY IN THE MAMMALIA
}

\author{
GEO. S. HUNTINGTON \\ Columbia University
}

TWO TEXT FIGURES AND FIVE COLORED PLATES

In the course of an extensive investigation into the phylogeny and morphology of the vertebrate respiratory apparatus, the vascular supply of the mammalian lung required a detailed review of the early ontogenetic stages in relation to their influence on the architectonics of the developing organ. During the progress of this study certain early phases in the development of the pulmonary arteries in the cat and albino rat showed conditions which warrant an important modification of the accepted genetic interpretation of the main pulmonary arteries of the mammalia as developing through caudally directed buds or outgrowths from the ventral portions of the sixth aortic arches. Since these results bear directly on the phyletic significance of these vessels and of the mammalian respiratory tract as a whole, a preliminary excerpt from the more extensive work now nearing publication is here presented. In embryos of the cat measuring from $7 \mathrm{~mm}$. up the pulmonary artery is found arising from the ventral portion of the sixth arch of each side, and descending as a complete and continuous vessel to supply the developing lung. The descriptions of these later stages fail, however, to take cognizance of a distinct antecedent phase in the development of the pulmonary artery, in which the entire vessel, prior to its subsequently attained connection with the sixth arch, is the product of a longitudinal anastomosis between a series of transversely directed ventromedial branches of the dorsal aortae caudal to their point of connection with the sixth arch. The critical stages are encountered in cat embryos of between $3 \mathrm{~mm}$. and $6 \mathrm{~mm}$. crownrump measure. Considerable variation is found in individual 
examples in regard to the relation between the events of this early period and the total length of the embryo, probably dependent largely upon differences in the measurements as influenced by the individual variation in the degree of the body curve.

Plate 1 shows the right side of a corrosion reconstruction of the pharynx and arterial arches in a $6-\mathrm{mm}$. cat embryo (C.U.E.C., series 889) and represents the earliest stage in the accompanying series of four models here selected as illustrations. The branchial pouches I to $\mathrm{V}$ are indicated fully, and IV is differentiated clearly from $\mathrm{V}$ by a deep narrow groove. The pulmonary anlage consists of a short blunt ventral evagination in wide communication with the oesophagus, its caudal termination showing a mere indication of bifurcation.

The first and second aortic arches are already discontinuous and broken up into their cranial terminals. The third and fourth arches are complete, the former being the larger of the two. On the fourth arch the point of confluence of its ventral and dorsal anlagen is still indicated by a narrowed isthmus and an irregular ventrocranially directed spur.

The formation of the rudiments of a fifth arch $(5,5)$ and the development of the sixth arch $(6,6)$ are still in their inception. The ventral anlage of the fifth is represented by a short blunt projection from the caudal border of the fourth arch, just ventral to the fourth pouch. The dorsal element of the fifth appears as a similar somewhat smaller protrusion from the dorsal aorta, caudal to its connection with the fourth arch. The ventral and dorsal beginnings of the sixth arch are clear. The former appears as a short rounded process arising from the caudal margin of the fourth arch, midway between the ventral rudiment of the fifth arch and the truncus.

The dorsal rudiment of the sixth arch arises from the dorsal aorta, extending craniad as a short spur. This I shall designate as the cranial member in a series of aortic derivatives which, inosculating in a capillary network, form what may be defined as the postbranchial pulmonary plexus, in view of the part it takes in the development of the pulmonary artery, as described in detail below. The succeeding two components $(7,8)$ follow 
in close proximity to 6 , and the three branches form together a broad aortic connection, pierced by two rounded foramina. From this a network of capillaries extends ventrad into the tracheogular area. The ninth aortic derivative enters the plexus considerably further caudad opposite to the pulmonary evagination.

Plate 2 shows the right side of the same region in another 6-mm. embryo (C.U.F.C., series 885), in which the reconstruction has followed the ectal surface of the pharyngeal epithelium. The IV th pouch has enlarged, especially in its sagittal dimension, and the $V$ th appears more distinctly as its caudal prolongation, owing to the broadening out and shallowing of the deep narrow sulcus separating the IV th and Vth evaginations in the preceding embryo (scries 889 , pl. 1).

The first and second aortic arches are, as before, interrupted, the third and fourth are continuous, and the sixth has become established as the completed pulmonic arch.

Compared with the preceding stage (pl. 1), the area caudal to the fourth arch has undergone a considerable and significant rearrangement, owing primarily to the increased surface of the pharyngea' wall corresponding to the IVth and Vth evaginations, and to the completion of the sixth aortic arch.

The ventral extremities of the aortic arches have joined in an extensive bulbus which is definitely set off against the truncus. The sixth arch arises on each side as a continuation of the caudolateral angle of the bulbus, curves caudodorsad to pass on the medial surface of the Vth pouch, and enters the dorsal aorta by a wide, irregularly expanded terminal which develops from the cranial end of the postbranchial pulmonary plexus of the preceding stage. With the completion of the sixth arch and the enlargement of the pharyngeal area IV to $\mathrm{V}$, the fourth arch moves further craniad relative to the pharynx as a whole. It is lodged in the depth of the third branchial groove and overlapped ectally by the tip of the third pouch.

The rudiments of the fifth arch now appear (pl. 2, 5,5) in the space occupied by the IVth and Vth evaginations and framed by the fourth and sixth arches, the corresponding portions of 
the bulbus and the dorsal aorta. The dorsal anlage of the fifth arch is seen as a short spur arising from the dorsal aorta between 4 and 6 . The ventral rudiment of the fifth arch forms a somewhat longer projection from the beginning of the ventral segment of the pulmonic arch. Both the dorsal and ventral fifth arch anlagen occupy exactly the same horizontal level, corresponding to the groove between the IVth and Vth branchial pouches.

The ventral protons of the fifth and sixth arches, which are seen in series 889 connected with the caudal border of the fourth arch (pl. 1, 4, 5), have become joined in series 885 and separated from the fourth arch, the extension caudad of the sixth arch carrying the ventral anlage of the fifth arch with it into the position and relations shown in plate 2 . The pulmonary development in embryo 885 is relatively far advanced. The tracheal tube has separated from the oesophagus in its distal third, and the larger right lung already shows the beginning budding of the eparterial, cardiac, and first and second ventral hyparterial bronchi. The postbranchial pulmonary plexus has extended ventrad into the pulmonary area and is closely associated with the cranial portion of the developing lung, while a number of isolated vascular islands indicate the line of its future extension into the caudal districts. The dorsal aortic tributaries to the plexus are indicated in the reconstruction, numbered 7 to 12 . The cranial end of the plexus is still connected with the dorsal aortic root of the sixth arch by the same broad capillary confluence observed in the preceding embryo 889 , and the same intervals between 6,7 , and 8 are retained as wider meshes of the reticulum. Aortic branch 10 is of notable length and ealiber, and reaches the plexus near the commencement of its distal third. Branches 9,11 , and 12 are connected with the plexus through delicate capillary anastomoses not reproduced in the model.

In comparing the two models shown in plates 1 and 2 , the following changes are significant:

1. The increase in the longitudinal measure of the lateral pharyngeal wall carrying the IVth and Vth evaginations has approximated them more closely to the cranial elements of the postbranchial plexus, and hence to the dorsal anlage of the sixth arch. 
2. At the same time the ventral anlage of the sixth aortic arch, carrying the ventral rudiment of the fifth arch with it, has moved caudad, opening up an interval between it and the fourth arch in which the two rudiments of the fifth arch are brought to face each other at the level of the ectal groove separating the IVth and Vth pouches.

3. The sixth arch has thus acquired an independent ventral origin from the aortic bulbus.

4. This shift and the accompanying further development has brought the cranial end of the postbranchial plexus, carrying the dorsal anlage of the sixth aortic arch, nearer to the dorsal end of the fourth and the dorsal rudiment of the fifth a ch, while the corresponding ventral interval has been lengthened by the separation of the fourth and sixth arches at the bulbus and the downward extension of the latter vessel. These shifts of the dorsal and ventral pulmonic anlagen balance each other and thus bring the two anlagen to the same level in the angle formed between the last pharyngeal evagination and the lateral wall of the postbranchial intestine.

5. The sixth aortic arch differs, therefore, from the preceding arches in the mode of development of its ventral and dorsal anlagen. While the former shares with the remaining aortic arches an ultimate origin from the aortic bulbus, the latter is from the beginning part of a plexus organized in direct relation to the developing lung, from which it separates only secondarily to furnish the material for the establishment of the Botallian duct.

The important facts in the development of the complete pulmonary artery in relation both to the sixth arch and to the post-branchial pulmonary plexus will be considered after the remaining stages here selected for illustration have been described.

Plate 3 shows the right side of a lumen reconstruction of the pharynx and aortic arches in a $4-\mathrm{mm}$. cat embryo (C.U.E.C., series 771). The first and second arterial arches are interrupted, the third and fourth complete. There is no trace of a ventral rudiment of a fifth arch, derived either from the fourth or from 
the sixth arch. But a well-developed dorsal anlage of the fifth arch arises from the aorta, and is lodged in the distinct transverse sulcus separating the IVth and Vth pouches. Abutting against the blind ventral termination of the rudimentary fifth arch, between it and the ventral pulmonic anlage, is an isolated arterial island, which might, in the course of further development, either form a continuation of the fifth arch ventrad or join the ventral element of the sixth arch under cover of the Vth evagination in completing the pulmonic arch. In view of the course of development of the pulmonary artery in a number of embryos examined, I am inclined to accept the latter interpretation of the isolated vascular island in question for reasons stated in detail below. (cf. pp. 174, 175.)

The sixth arch is outlined clearly by its dorsal aortic and ventral bulbar components, which have not yet fused caudomesal to the Vth pouch. The dorsal anlage of the pulmonic arch again arises from the dorsal aorta in continuity with the cranial end of the postbranchial pulmonary plexus. The foramen between dorsal 6 and 7 , previously noted in series 889 and 885 , appears somewhat elongated. The plexus further caudad receives four additional aortic branches ( 8 to 11) which inosculate on the walls of the intestinal tube and developing lung. The latter corresponds to the stage shown in series 885 . The caudal segment and bifurcation of the trachea are free from the oesophagus. The cast of the right pulmonary lumen shows the beginnings of the eparterial, cardiac, first and second ventral hyparterial buds. The ascending bud from the first ventral hyparterial appears on the tree of the left lung. The ventral proton of the sixth arch arises from the right caudal angle of the bulb, close to its connection with the fourth arch, and descends along the entire ventral margin of the IVth and Vth pouches to end in a blunt recurved hook caudal to the above-described isolated arterial anlage.

Finally plates 4 and 5 show the right and left views of a reconstruction of the same region in another $4-\mathrm{mm}$. cat embryo (C.U.E.C., series 773), in which the model follows the ectal line of the intestinal epithelium. 
1. Plate 4. Right side of model 773. The fourth arch is complete, but is partly reduplicated in its dorsal portion. I am inclined to assign to the smaller caudal element completing the foramen the tentative value of a rudimentary and incomplete fifth arch. This interpretation is in part supported by the conditions illustrated in embryo 889 , in which pouches IV and $\mathrm{V}$ appear as distinct pharyngeal evaginations separated by a sharp narrow sulcus (pl. 1). If the arterial spurs 5 to 5 were joined, connecting the fourth arch with the dorsal aorta, the resulting fifth arch would occupy this groove between the IVth and Vth pouches, and the theoretical postulates for a fifth branchial arch and artery would be met.

In embryo 773 (pl. 4) the IVth and Vth pouches are practically confluent on both sides, and a fifth branchial arch is wanting. The dorsal rudiment of the fifth aortic arch may be considered to have moved cephalad over the smooth ectal surface of the last pharyngeal evagination, instead of lodging in a groove between the IV th and Vth pouches, and to have become partially submerged in the fourth aortic arch, forming the caudal boundary of its foramen. Ventral to this a blunt spur from the fourth arch (not labeled in the plate) agrees with the ventral rudiment of the fifth arch (5) found on the right side of embryo 889 (pl. 1).

The elements of a right fifth arch in series 773 appear to approach the conditions described by Zimmerman (2) in man. They also resemble the vessel described and figured in a $6.5-\mathrm{mm}$. pig embryo by Reagan (16, p. 497, fig. 15), who considers it, as well as Zimmerman's case, merely as division of the fourth arch.

The right sixth arch of series 773 is not yet completed. The shorter dorsal component arises from the dorsal aorta by a broadly expanded root, indicating the incorporation of some of the cranial elements of the postbranchial plexus, as in the preceding instances. The ventral anlage of the sixth arch descends from the bulb as a long vessel (cf. series 771, pl. 3), which, as it turns dorsad under cover of the Vth pouch, sends a blunt cone-shaped spur caudad toward the postbranchial plexus. In contrast to the preceding instances, the plexus has lost its direct 
connection with the dorsal root of the sixth arch. It is now supplied by four caudal aortic branches ( 7 to 10), which inosculate on the dorsal and lateral walls of the intestinal canal and lung. The latter is approximately in the same stage of development as series 771 (pl. 3).

2. Plate 5. Left side of model 773. The second aortic arch is still continuous. The IVth and Vth branchial pouches are practically merged, as on the right, into a single evagination. The rudiment of the fifth arch is represented by two short spurs arising from the dorsal aorta in the interval between the fourth and sixth arches. There is no corresponding ventral fifth anlage. The two sides of the reconstruction suggest that the practical confluence of the IVth and Vth pouches, and the consequent elimination of the fifth branchial arch, are factors bearing on the extreme reduction of the fifth aortic arch.

I can completely endorse the opinion expressed by Coulter $(13$, p. 590). "The facts observed point to the conclusion that ordinarily no fifth aortic arch is completely developed in the cat, and it seems more than probable that the incomplete development and uncertain character of the fifth aortic arch is merely an expression of the incomplete development of the fifth branchial arch." The sixth aortic arch has been completed by junction of its ventral and dorsal components under cover of the last pharyngeal evagination. The dorsal element, forming the anlage of the ductus arteriosus, has a double connection ( 6 and 7$)$ with the aorta. The caudally directed spur of the ventral anlage, noted on the right arch (pl. 4), has on the left side effected a junction with the cranial and ventral portion of the postbranchial plexus, and serves now as the main channel carrying the blood from the ventral segment of the pulmonic arch to the foregut and developing lung. In conformity with this rearrangement the postbranchial plexus shifts further ventrad to the dorsolateral aspect of the lung. It begins to lose its multilocular character of a capillary plexus with the development of a larger central channel, now in direct continuity with the ventral segment of the sixth arch, both together constituting the bed for the development of the definite pulmonary artery. 
The plexus still has numerous connections ( 8 to 14 ) with the dorsal aorta, caudal to the Botallian duct $(6,7)$, but they appear reduced in caliber, as if drawn out by the shift ventrad of the main channel into the line of the caudal continuation of the ventral pulmonic arch. The plexus as a whole is in the process of abandoning its primary multiple aortic connections and of transferring to the new line of the future pulmonary artery, initiated by its junction with the caudal spur from the ventral segment of the sixth arch.

GENERAL CONSIDERATIONS AND SUMMARY

\section{Morphogenesis}

It appears, on the evidence presented by the earlier stages in the cat, that the mammalian pulmonary arteries do not arise primarily as buds or outgrowths from the ventral segments of the two sixth aortic arches, and that they do not attain their destination by a process of continuous growth caudad, but that they develop by the concrescence of a number of originally independent vascular anlagen, which obtain a secondary connection with the sixth arch of each side, and thus lead to the establishment of the definite condition.

Caudal to the last pharyngeal evagination, the early perigular vascular spaces organize into a series of irregular channels opening into the dorsal aortae, which then appear to give origin, fairly symmetrically on the two sides, to from four to eight horizontal ventromedial branches directed toward the postpharyngeal intestinal tube, on which they form an inosculating capillary reticulum. With the development of the pulmonary anlage, this meshwork occupies the oesophageotracheal gutter and its distal elements spread over the lung-buds, forming a primitive pulmogular plexus. While this is organizing, the sixth aortic arch is laid down caudal to the last pharyngeal evagination. It develops, as do the remaining aortic arches, by anlagen which connect early with the dorsal and ventral aortae and appear hence as outgrowths or buds derived from them. These become joined to vascular islands developed independently along the 
line of the branchial arch. The ventral pulmonic anlage appears first as a blunt projection attached to the ventral extremity of the fourth aortic arch, close to its connection with the aortic bulb, to which its origin becomes subsequently transferred. It extends, partly by its own growth, partly by the incorporation of locally formed vascular spaces lying in its path, caudodorsad, along the ventral and caudal border of the last pharyngeal evagination, finally coming to occupy the mesal surface of the Vth pouch. The dorsal anlage of the sixth aortic arch arises from the dorsal aorta and constitutes at first the cranial component of the pulmogular plexus, gaining a greater independence from the latter as the sixth aortic arch becomes defined, and the plexus caudal to this point passes ventrad into more intimate relation with the developing lung. The dorsal and ventral anlagen of the pulmonic arch gradually approach each other in the manner described and join under cover of the last branchial protrusion to form the completed channel of the sixth arch. The method by which this junction is finally accomplished constitutes one of the most important steps in the development of the pulmonary artery. The two anlagen do not meet in an end to end fusion, but the dorsal component joins the longer ventral channel some distance above the latter's blind termination. The result is that, when the sixth arch is completed, its ventral segment is provided with what appears as a caecal outgrowth, directed caudad, toward the cranial end of the postbranchial pulmonary plexus. In the interim the latter has formed its main longitudinal channel, the proton of the future pulmonary artery, which becomes completely established by junction with the blunt ventral appendage of the sixth arch.

The apparent 'outgrowth' from the sixth arch, described in the current accounts as leading to the development of the pulmonary artery by a continued extension caudad, is therefore nothing but the blind end of the original ventral anlage of the sixth arch, left as an appendage when the arch is completed by meeting the extremity of the dorsal anlage in the manner above described. The main pulmonary artery develops independently of the sixth arch by the organization of a distinct arterial channel 
in the ventral portion of the postbranchial pulmonary plexus. The so-called 'outgrowth' from the sixth arch serves merely as the point of junction at which, after coalescence with the pulmonary plexus, the blood is carried from the ventral segment of the sixth arch into this prepared channel of the pulmonary artery. The 'outgrowth' would be more correctly defined as the pulmonary arterial 'tap' or 'approach' of the sixth arch.

This ontogenetic history of the sixth arch in its relation to the development of the pulmonary artery is uniformly encountered in embryos of the cat between $4 \mathrm{~mm}$. and $6 \mathrm{~mm}$. crownrump measure. The steps involved can be followed in the preparations selected to illustrate this paper, and are indicated schematically in the accompanying diagrams (text figs. 1 and 2).

Plate 1 (series 889) shows the initial stages in the development of the sixth arch. The ventral anlage (6) appears as a blunt protuberance incorporated in the ventral end of the fourth arch. The dorsal anlage (6) arises from the dorsal aorta in direct connection with the cranial end of the primitive pulmogular plexus, which occupies the dorsolateral wall of the postpharyngeal intestine and hardly extends as yet to the pulmonary bud.

In plate 3 (series 771) the longer ventral and shorter dorsal components of the sixth arch have formed and approach each other, encircling the Vth pouch. As previously stated, I regard the isolated arterial space, situated between the end of the rudimentary fifth arch and the ventral anlage of the sixth, as destined to be incorporated in the latter, and to furnish the link which, in further development, would have completed the arch by concrescence with the dorsal anlage under cover of the Vth pouch. If this had occurred, the actual blind end of the ventral anlage of the sixth arch (to which the short dotted leader runs in the plate) would be left as an appendix projecting from the sixth arch caudad toward the cranial end of the postbranchial plexus.

In plate 4 (series 773 , right side) the ventral anlage of the sixth aortic arch is again very long, the dorsal short. It may be fairly assumed that the former, by parasynaptic accretion of a vascular island similar to the isolated space shown in plate 
3 , has been carried further dorsad along the mesal side of the last branchial evagination, leaving its original terminal as the blind appendage seen extending caudad.

Plate 2 (series 885) shows the condition which completion of the sixth aortic arch would have produced in the preceding

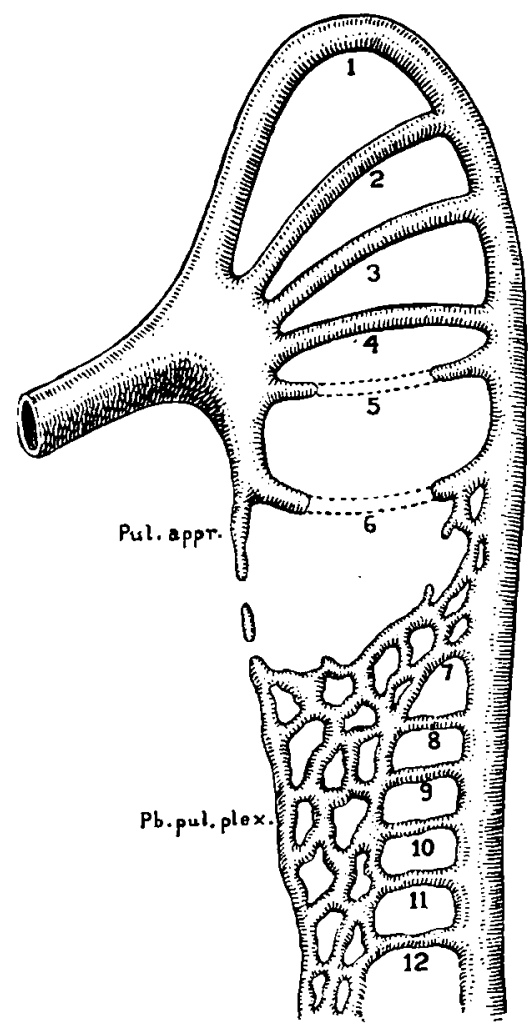

Figdre 1.

Figs. 1 and 2 Schemata of the development of the aortic arches, postbranchial pulmonary plexus and pulmonary artery. Fig. 1, early stage; fig. 2, later stage.

embryo, leaving the blind appendix attached to the ventral segment of the arch.

Finally, in plate 5 (series 773 , left side) the junction of this appendix with the cranial end of the postbranchial pulmonary plexus has occurred, and the definite permanent path of the pulmonary artery has been established, leading from the heart via the sixth arch to the lung. 
The successive changes which take place in the postbranchial pulmonary plexus involve:

1. A gradual shift of the plexus ventrad into closer proximity to the developing lung. Plates $1,5,4,3,2$, show the stages in this process, in the order named.

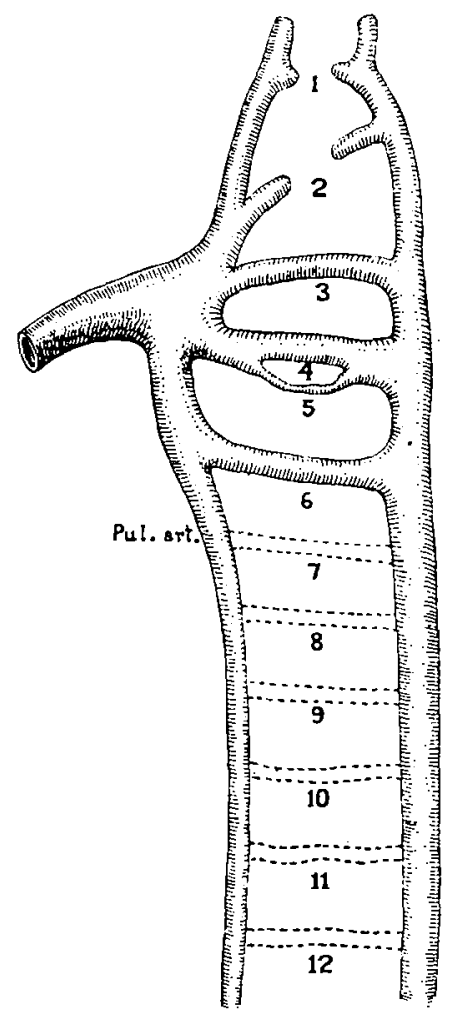

Figure 2.

1 to 6 , aortic arches; 7 to 12 , dorsal aortic branches. Pb. pul. plex., postbranchial pulmonary plexus; Pul. appr., pulmonary approach of sixth aortic arch; $P$ ul. art., pulmonary artery.

2. This change from a dorsal to a ventral parapulmonary plexus is effected partly by a lengthening of its primitive connections with the dorsal aorta, partly by the interruption of a number of them (pls. 2, 3).

3. The establishment of a larger, better-defined channel within the ventral segment of the plexus, which is to serve as the fundament of the main pulmonary artery. 
4. The gradual separation of the dorsal anlage of the sixth arch from the cranial extremity of the postbranchial pulmonary plexus, leaving the former as the basis for the Botallian duct (pl. 4).

5. The junction of the cranial extremity of the postbranchial pulmonary plexus with the above-described appendage to the ventral segment of the sixth arch, thus establishing the definite path of the pulmonary artery (pl. 5).

The origin of the pulmonary artery shif ts, therefore, ontogenetically from the dorsal aorta first to the rudiment of the Botallian duct and then to the ventral segment of the sixth arch, simulating an 'outgrowth' from the latter, but actually signalizing the final step in the concrescence of the branchial and postbranchial elements entering into the composition of the adult vessel. This is illustrated by the following series in the order named: plates $1,3,2,4,5$.

The above-described phases in the ontogenetic history of the mammalian pulmonary artery, as illustrated in the cat, occupy a relatively short period in which they do not follow each other in a strict chronological order which is uniform for every embryo. In any individual one or another of the events comprised in the early development cycle of the pulmonary artery may make a precocious appearance or be delayed. Hence the examples here used as illustrations of each phase do not maintain their exact numerical order throughout the entire period, but are intended to cover all the events of the early stage as a whole. For example, in plate 5, closing the series, the postbranchial pulmonary plexus is still connected at numerous points with the dorsal aorta, although the anlage of the pulmonary artery has effected its junction with the ventral part of the sixth arch, while on the other hand, in plate 2 the separation of the postbranchial plexus from the aorta is far advanced, although the connection with the sixth arch is not yet established. The early period thus includes the completion of the sixth aortic arch, the formation of its ventral "outgrowth,' more properly defined as its 'pulmonary approach,' and the organization of 
the postbranchial pulmonary plexus developing concurrently as a whole, but with slight chronological variations in the appearance of these events in individual embryos.

\section{Phylogenetic considerations}

In their phyletic significance the early ontogenetic stages of the mammalian pulmonary artery place this vessel in direct serial line with the respiratory vascular channels of the lower vertebrates and outline the common vertebrate ground-plan for this portion of the haemal vascular system. The establishment of a respiratory apparatus, other than the cutaneous exchange of the blood gases, depends upon the morphological adaptations to this purpose of shorter or longer areas of the intestinal entoderm, whatever form the resulting structure may finally obtain in the different vertebrate classes. Modifications of the vascular system, adapting this entodermal respiratory derivative to its functional purpose, develop in correlation with the morphogenesis of the respiratory organ in response to the varying environmental and metabolic demands of the vertebrate types. The proximity and parallel course of the intestinal tube and aorta in the dorsal axial line naturally bring both structures into coöperation in the development of the respiratory tract, and branches of the dorsal aortae function from the beginning as the afferent respiratory channels. The concept is justified that in the prevertebrate and in the earliest vertebrate types the exchange of the gases of the body was carried on by a series of modified epithelial areas of the intestinal tube, perhaps extending over the greater part of the entire canal, and supplied by a corresponding metameric series of intersegmental afferent vessels from aorta. The numerous gill-slits of Amphioxus and the multiple internal gill-pouches of Cyclostomes (Bdellostoma, Myxine) support this assumption anong extant forms. The next step in vertebrate respiratory organization is, of course, based on the more favorable location of the cranial portion of the intestinal canal for the intake of the aerating water through 
the oral opening, and on the advantage offered by a reduced number of larger afferent vessels arising in close proximity to the heart. These two factors resulted in the specialization of the pharynx and the development of the branchial apparatus. With the acquisition and further elaboration of this highly concentrated respiratory organ, the series of the aortic arches develop as the sole afferent vessels in the higher water-breathing types, and the more caudally situated primitive multiple aortic afferents are suppressed or diverted to other functions of the digestive tract. With the final replacement of the branchial by the pulmonic type of respiration a rearrangement of the vascular relations is necessitated. This calls into service both the distal aortic arches and their connection with the truncus of the heart, and again resuscitates the series of the primitive aortic afferents supplying in the early phyletic stages the respiratory areas of that portion of the intestinal tube which now, as its postbranchial segment, forms the site of the final pulmonary evagination. In tracing this brief outline of the phylogenetic history of the pulmonary artery in the higher vertebrates, it is significant to note that in the perennibranchiate Amphibians, possessing both gills and primitive lungs, some concrete evidence is to be found in support of the view here expressed. Thus, Miller ( 5 a) describes the pulmonary artery in Necturus as arising from the combined channel of the efferent second and third aortic arches and sending small branches to the muscles of the pectoral region on its way to the lung. Williams (14) compares these pectoral branches to the large cutaneous branches of the pulmonary artery found in the frog. They might equally well be interpreted as primitive respiratory aortic branches which, with the development of the branchial apparatus, were diverted to the somatic supply, but which the appearance of the lung has in part swept into the newly organized pulmonary artery, in accordance with the ontogeny of this vessel outlined above. A definite answer as to the significance of the pulmopectoral branches of Necturus and of similar vessels in other forms calls for the detailed study of the early ontogeny of their pulmonary artery. 
Further, Williams (1.c., pp. 409-413) describes and figures instances in Necturus in which a lung is either entirely supplied by a caudocranially directed branch of the seventh intercostal artery, with default of the typical pulmonary artery, or receives pulmonary branches from the dorsal aorta supplementing a reduced pulmonary artery derived from the efferent branchials. Accessory pulmonary arteries arising from the coeliac, or from the mesenteric arteries have also been recorded in the frog by Mudge (11) and Warren (3).

In several Lacertilian reptiles (Iguana, Cyclura) the lung receives normally one or more accessory pulmonary arteries from the aorta or from the mesenteric arteries, and the adult arrangement of the entire pulmonary arterial supply corresponds strikingly to the above-described mammalian stages in embryos of the cat.

Hyrtl describes similar constant accessory pulmonary arteries in the Ophidia arising from the aorta or from some of its splanchnic branches (oesophageal, gastric, hepatic). These scattered and rather incidentally recorded observations in the lower vertebrates could unquestionably be greatly multiplied by a systematic investigation covering a wider range of material and types. They constitute, in my opinion, a group of very important facts bearing directly on the phyletic path followed by the mammalian lung and its vessels, and closely linked with the ontogenetic history of the pulmonary artery as outlined above. I find myself obliged to differ emphatically from the opinion expressed by Williams in summing up his observations on Necturus (1.c., p. 414) when he says: "The results of further investigation indicate that the occurrence of pulmonary branches of the aorta in the various classes of vertebrates has an embryological rather than an evolutionary significance. The connectivetissue pathway being provided, capillary branches from the adjacent vessels will enter it, and occasionally, as in these Necturus specimens, certain of them will become very large, and notable as anomalies." This view, in my judgment, deliberately throws overboard the only rational ontogenetic and comparative anatomical guiding line which we possess for the sound interpretation 
of reversional phylogenetic variation. It is true that the vertebrate organization is provided throughout with abundant 'connective-tissue pathways,' and the primitive dorsal mesentery of the intestine is among the most archeal of these structures. The entire vertebrate vascular system owes its origin to the inherent potency of the mesenchyme to differentiate locally all the components of the vascular anlage. A developing channel does not simply 'enter' a 'connective-tissue pathway' serving merely passively as the road along which an extension from preexisting adjacent vessels travels carrying a structure of foreign derivation into new territory. The 'pathway' itself furnishes the material for the construction of the new vessel on the spot by mesenchymal differentiation. This does not occur by chance or at random, nor because a 'pathway' happens to be available, in a place where the entire territory is potentially 'pathway' in the sense of providing the cellular basis for the development of a vessel, if the proper impulse for such development exists. This determinant is offered by the definite fundamental groundplan underlying all vertebrate angeiogenesis, however greatly it may become modified with the branching of the parent stem.

Certainly, a set of vessels which develop uniformly during the mammalian ontogeny, which constitute part of the normal vascular system in some of the lower vertebrates, which appear as variants in individuals of different vertebrate classes, and which, moreover, fit into a common genetic plan of vertebrate organization, are not the outcome of a haphazard accidental wandering of their components into strange and unusual 'connective-tissue paths'. They develop in strict conformity to the impulse derived from the entire ancestral background of the individual which we define as Heritage and recognize as the recording angel of evolution.

To return to the case here under discussion, certain human variations of the pulmonary arteries, in addition to those of the bronchial arteries, merit consideration in this connection and find their explanation in the embryonic history of these vessels. To this group belong the following, recorded mostly by Krause (19), Schwalbe (18), and Förster (17): 
1. Origin of the left pulmonary artery from the left subclavian, or anastomoses between the two vessels.

2. Origin of the right pulmonary artery from the innominate trunk.

3. The right subclavia arising from the bifurcation of the pulmonary trunk.

4. The left subclavia forming the continuation of the Botallian duct.

5. Of special significance are the cases collected by Peacock (20), in which the aortic arch defaults or is interrupted and the descending aorta forms a continuation of the pulmonary artery. Herxheimer (18, p. 461) describes and figures a case in which the aorta gave origin to the innominate, left carotid, and left subclavian arteries and then ended blindly. The pulmonary artery continued directly through an enlarged Botallian duct into the descending aorta, supplying intercostal and abdominal branches, and dividing into the common iliac vessels.

The origin and variations of the bronchial arteries, and the presence of anastomoses or larger connecting channels between them and the pulmonary arteries, likewise depend on the organization of the early postbranchial pulmonary plexus.

Finally, the ontongenetic facts here recorded have an important bearing on the phylogenetic interpretation of the intrapulmonary architecture of those mammalian types in which the prevalent dorsolateral relation of the main pulmonary artery to the stembronchus and its primary derivatives is exchanged for a course in which the vessel passes ventral to one or more of the primary ventral bronchi. This is the normal relation of the structures in the right lung of Alouatta seniculus and on both sides in Sphingurus prehensilis. It is recorded as a more or less frequent variation in individuals of a number of mammalian genera:

Primates:

Man.

Macacus erythraeus.

Macacus nemestrinus.

Cercocebus sinicus.

Hapale rosaria. 
Insectivores:

Pteropus edulis.

Vesperugo pipistrellus.

Erinaceus europaeus.

Carnivores:

Phoca vitulina.

Felis lynx.

Ungulates:

Catoblepas gnu.

Capra ibex.

Bos taurus.

\section{Edentates:}

Dasypus novemcinctus.

Dasypus setosus.

\section{Mono remes:}

Echidna aculeata.

The existence of these atypical relations of the pulmonary artery to the ventrolateral derivatives of the stembronchus point clearly to the potential development in the mammal of a secondary ventral arterial channel, supplementary to the main dorsolateral pulmonary artery, and capable of partly or wholly replacing the same, either regularly in a few species (Alouatta, Sphingurus), or as an individual ontogenetic variation in a more extended range of mammalian types. The evidence now afforded by the organization of the postbranchial pulmonary plexus demonstrates the potential development of intrapulmonary arterial lines both ventral and dorsal to the axis of the early pulmonary cavum which constitutes the basis of the future stembronchus and its primary branches.

While the dorsal arterial path becomes in the vast majority of mammalian types the typical and more constant channel, following the dorsolateral circumference of the stembronchus and intersecting its primary derivatives on their dorsal aspect, the morphogenetic history of the mammalian pulmonary artery clears the field of hypothetical considerations by furnishing a plan of intrapulmonary arterial development according to which either the dorsal or ventral line is able to develop, either exclusively or predominately. 


\section{BIBLIOGRAPHY}

Since the appearance of Zimmermann's (2) pioneer publication in 1889 , the site of the developing pulmonary artery in the mammalian embryo has been studied in detail by a number of investigators owing to the interest aroused by the question of the fifth aortic arch and the ensuing discussion regarding the nature of the post- or ultimobranchial pharyngeal evagination. It is, as stated, generally assumed that the mammalian pulmonary artery develops as a bud or outgrowth from the ventral segment of the sixth aortic arch.

His (1 a) in 1885 refers briefly to the development of the pulmonary arteries as arising early from the caudal aortic arch of each side, in human embryos of between $4.2 \mathrm{~mm}$. and $5 \mathrm{~mm}$. total length (fig. 121 of text; Taf. Ix. figs. 4 and 5 of Atlas). In 1887 he published $(1 \mathrm{~b})$ the first detailed account of the development of the lung in the human embryo, in which he describes the appearance of the anlagen of the pulmonary arteries as about coinciding with the completion of the last aortic arches, arising from these at the level of the future arytenoids and descending steeply along the ventral border of the tracheal anlage. $\mathrm{He}$ concludes his account of the early ontogenetic period of these vessels with the statement (p. 102), "Über das Verhalten des untersten Gefässendes während der frühen Entwicklungsstufen vermag ich keine entscheidenden Angaben zu machen."

His' account has been handed down practically unchanged, except for the numerical value assigned to the pulmonic arch in the series of the aortic arches, and forms the basis for the modern genetic interpretation of the vessel.

Narath, who published an extensive monograph on the comparative anatomy of the mammalian lung (4) in 1901, devotes a special paragraph (1.c., pp. 283, 284) to the development of the pulmonary artery in the rabbit. He follows the stereotyped account, describing the vessel as arising in embryos of the eleventh day from the lowest point of the ventral segment of the sixth aortic arch and descending along the pulmonary anlage at first in complete symmetry with the same. He does not refer to the 
existence of any contributions from the dorsal aortae. He gives a somewhat schematic figure (tab. I, fig. 2) of a cleared preparation of a $7 \frac{2}{5} \mathrm{~mm}$. rabbit embryo, showing the relation of the artery to the trachea and lung-bud. There is no reference to any other source of origin for the pulmonary artery.

Bremer, in his two earlier publications ( $8 \mathrm{a}, 8 \mathrm{~b}$ ), accepts the pulmonary arteries as continuous symmetrical outgrowths, one from each pulmonary arch. The two papers deal mainly with the mechanical aspects of the main pulmonary truncus in its torsion about the aortic bulb, around which the sixth arches are wound, and the resulting location of their points of connection with the proximal artery. He describes the proximal fusion of the two pulmonic arches by absorption of their walls brought into contact by the twist, thus lengthening the truncus at their expense and moving the point of bifurcation continually farther from the heart. In addition to this fusion of the ventral segments of the sixth arches, Bremer describes the approximation of the pulmonary arteries and the development of an anastomosis between them. He also speaks of the pulmonary arteries as developing in a capillary network. In his third paper (8 c) Bremer describes the pulmonary arteries in embryos of the rabbit as arising, not from the pulmonary arches, but from a ventral aortic net, which extends beyond the arch. He says (1.c. p. 126): " . . . . this entension of the ventral aortic net forms well defined pulmonary arteries, one on each side before the pulmonary arch exists; the pulmonary artery is in no sense a branch of the pulmonary arch, and moreover, in the strictest sense, the arch extends only from the dorsal aorta to the pulmonary artery, the ventral part of the vessel usually called the arch is really the ventral aorta. The persistent pulmonary arteries are entirely ventral; they have been joined during embryonic life by branches from the dorsal aorta, but such branches are only temporary."

Bremer sums up his conclusions (1. c. p. 127) as follows:

A further extension of the plexus of the ventral aorta, situated between the floor of the pharynx and the dorsal wall of the pericardial cavity, but prevented from crossing the median line by the presence 
of the median pharyngeal outgrowth to form the trachea, extends to the lungs as the pulmonary arteries, which are later joined by vessels springing from the dorsal aortae. These vessels, which may be double and plexiform, constitute the fifth (and sixth) arch.

These highly interesting observations of Dr. Bremer's on rabbit embryos do not agree with my findings in cat and rabbit embryos, as described in the body of this paper. On the evidence furnished, at least by my material, I am obliged to ascribe real morphological value to the ventral anlage of the sixth arch, which cannot be merged into a caudal extension of the ventral aorta.

As shown in the above-described series of cat embryos, the sixth arch is either well on its way to completion (pls. 3 and 4) or actually has joined the dorsal anlage before the pulmonary artery, still included within the postbranchial plexus, has united with the process from the sixth arch. This union (pl. 5) I must regard as the final step in the establishment of the definite path of the persistent pulmonary artery.

As regards the contributions from the dorsal aortae, Bremer regards them as forming the fifth and sixth arches, which do not arise from the ventral aortic net.

In a subsequent communication ( $8 \mathrm{~d}$ ) Bremer quotes a short article published in the Russian language by Fedorow in the "Communications of the Military Med. Akad." St. Petersburg, vol. 22 , no. 1, 1911, describing the origin of the pulmonary arteries in the guinea-pig. As appears in the translation furnished very kindly by Dr. Bremer of extracts from this inaccessible paper, Fedorow describes the pulmonary arteries as arising in embryos of the eighteenth day (30 somites) from the fourth aortic arches of each side.

They begin near the truncus arteriosus ventral to the middle part of the pharynx, which is quite large at this point. The arteries run caudally on the ventral surface of the oesophagus, dorsal to the pericardial cavity, and quite near to each other. Further down, the oesophagus appears compressed laterally, and the arteries lie lateral to its ventral part, which projects in the form of a pointed keel. The pulmonary arteries end blindly, traversing about 20 segments $(240 \mu)$. In another embryo of the same age, with 29 somites, the arteries extend 
further, their diameter varying at different points, and it may be anastomose with the vessels of the oesophagus. Similar anastomoses frequently occur later. One notices the double origin of both arteries from their corresponding arches, and they may even join one another near the arch. Island formation occurs along the course of the arteries.

In the embryo of the nineteenth day, with 32 somites, the third and fourth pairs of aortic arches are present, the sixth pair represented by blind growths both from the dorsal aortac and from the truncus arteriosus. The delicate pulmonary arteries begin from the sixth pair as short growths. Properly, they are the elongated aa. pulmonales of the earlier stages. They run caudally ventrolateral to the oesophagus, and anastomose with its vessels.

Fedorow's description of the first anlagen of the pulmonary arteries arising in the guinea-pig from the "medial wall of the fourth arches, near the truncus arteriosus," corresponds entirely with the condition observed in the cat (cf. pl. I, 6, pp. 168169), prior to the development of a separate point of origin from the extended aortic bulbus, as the now independent vèntral anlage of the sixth arch. I take it that this is what the Russian observer implies when he decribes the pulmonary arteries of his 32-somite embryo as arising from the sixth arches as small growths: "Properly, they are the elongated a.a. pulmonales of the earlier stages."

Fedorow speaks of anastomoses between the pulmonary arteries and the oesophageal vessels, but does not assign to the latter any share in the formation of the definitive pulmonary artery, which remains an outgrowth from the aortic arches.

Coulter $(13$, p. 587), describing a $5.6-\mathrm{mm}$. cat embryo (series 110 of the Columbia University Collection), says: "Each pulmonary arch joins the dorsal aorta by three distinct roots, not clearly shown in the figure." This evidently refers to the cranial portion of the postbranchial plexus and its connection with the dorsal anlage of the sixth arch, which, as above described, is primarily a plexus derivative. Further in the same paper (p. 587), in describing a 7-mm. embryo (series 138, C. U. E. C.), he finds that "the dorsal end of the sixth aortic arch is very large, and on the right side shows a peculiar grooving which is suggestive of a division into two much longer roots than found elsewhere." 
Finally (p. 590) Coulter concludes: "It may well be that the anastomoses and irregular roots about the base of the pulmonic arch which have been so generally described in the mammalia are evidence of an assimilation of the fifth aortic arch into the pulmonic, beginning at their dorsal extremities. . . . The dorsal root of the pulmonic arch in every case, from its first appearance until after the buds of the pulmonary arteries arise, was found to be pierced by two or more 'islands.' The significance of this has been referred to above."

These are the only passages which I can find in the literature indicating that at least the cranial extremity of the postbranchial pulmonary plexus has been observed and noted in connection with the dorsal anlage of the sixth arch, although its entire organization and s gnificance escaped recognition.

1 Hrs, WM. 1885-1887. (a) Anatomie menschlichen Embryonen. III, S. 186. 1885.

(b) Zur Bildungensgeschichte der Lungen beim mensehlichen Embryo. Arch. f. Anat. und Phys., Anat. Abth. II. Heft. 1887.

2 Zimmermann, W. 1889. Utber einen zwischen Aorten und Pulmonalbogen gelegenen Kiemenarterienbogen beim Kaninchen. Anat. Anz., Bd. 4.

3 WarRen, E. 1900. A further note on a variation in Rana temporaria. Anat. Anz., Bd. 18, S. 122-123.

4 Narath, A. 1901. Der Bronchialbaum der Säugethiere und des Menschen. Bibliotheca medica, Abth. A, Heft 3.

5 Miller, W. S. 1905. (a) The vascular system of Necturus maculatus. Bull. Univ. Wisconsin, no. 33, pp. 213-214.

(b) The blood and lymph vessels of the lung of Necturus maculatus. Am. Jour. Anat., vol. 4.

6 LenmanN, H. 1905. On the embryonic history of the aortic arches in mammals. Anat. Anz., Bd. 26.

7 LEwis, F. T. 1904. (a) The intra-embryonic blood-vessels of rabbits from eight and one-half to thirteen days. Am. Jour. Anat., vol. 3.

(b) The fifth and sixth aortic arches and the related pharyngeal pouches in the rabbit and pig. Anat. Anz., Bd. 28.

8 BREMER, JohN L. 1902-1912. On the origin of the pulmonary arteries in mammals. (a) Am. Jour. Anat., vol. 1, no. 2, 1902.

(b) Anat. Rec., vol. 3, no. 6, 1909.

(c) The development of the aorta and aortic arches in rabbits. Am. Jour. Anat., vol. 13, p. III, 1912.

(d) An acknowledgement of Fedorow's work on pulmonary arteries. Anat. Rec., vol. 6, p. 491, 1912. 
9 Locy, W. A. 1906. (a) The fifth and sixth aortic arches in chick embryos, with comments on the conditions in other vertebrates. Anat. Anz. Bd. 29.

(b) The fifth and sixth aortic arches in birds and mammals. Cambridge, Mass. 1909.

10 Soulie, A., AND Bonne, C. 1908. L' Appareil Branchiale et les Arcs Aortiques, de l'Embr. de Taupe. Jour. de l'Anat. et de la Phys., no. 1.

11 MUdGe, G. P. 1908. An interesting case of connection between the lungs and systemic circulating system and of an abnormal hepatic bloodsupply in a frog. Jour. Anat. and Phys., vol. 33, pp. 54-63.

12 Tandler, Julius 1909. Uber die Entwicklung des V. Aortenbogens und der V. Schlundtasche beim Menschen. Anat. Hefte, no. 115.

13 Codlter, C. B. 1909. The early development of the aortic arches of the cat, with special reference to the presence of the fifth arch. Anat. Rec., vol. 3, no. 11 .

14 Williams, S. R. 1909. Anomalies of the pulmonary artery in Necturus. Anat. Rec., vol. 3, no. 7, pp. 409-414.

15 Reinke, E. E. 1910. Note on the presence of the fifth aortic arch in a $6 \mathrm{~mm}$. pig embryo. Anat. Rec., vol. 4, no. 12.

16 Reagan, Frank 1912. The fifth aortic arch of mammalian embryos; the nature of the last pharyngeal evagination. Am. Jour. Anat., vol. 12, no. 4.

17 Förster, Adadst 1865. Die Missbildungen des Menschen systematisch dargestellt. 2. Aufl. Jena. S. 145.

18 Schwalbe, Ernst Die Morphologie der Missbildungen des Menschen und der Tiere. III. Teil, III. Lief., 2. Abt., 4. Kapit. Herxheimer, Gotthold. Missbildungen des Herzens und der grossen Gefässe. Jena, 1910.

19 KrAdse, W. in Henle's Gefässlehre, 1868. Varietäten der A. pulumonalis, S. 76. Varietäten des Arcus Aortae., II, 9, S. 224.

20 Peacock, 1866. Malformations. British and Foreign med.-chir. Rev., vol. XXV. 1860.

Tr. Path. Soc., vol. XXVII. 1876. 


\section{PLATES}

\section{EXPLANATION OF PLATES}

$\mathrm{I}$ to $\mathrm{V}$, branchial pouches.

1 ti, 6 , aortic arches.

7 to 14, branches of thoracic aorta entering postbranchial pulmonary plexus.

$L$, pulmonary anlage.

Arteries-red. "Thyroid-green. 
PLATE 1

Series 889, C.U.E.C. 6-mm. cat, $\times 150$. (From a reconstruction by Virginia Kneeland.) 
PULMONARY ARTERY IN THE MAMMALIA

PLATE 1

GEO. S. EUNTINGTON

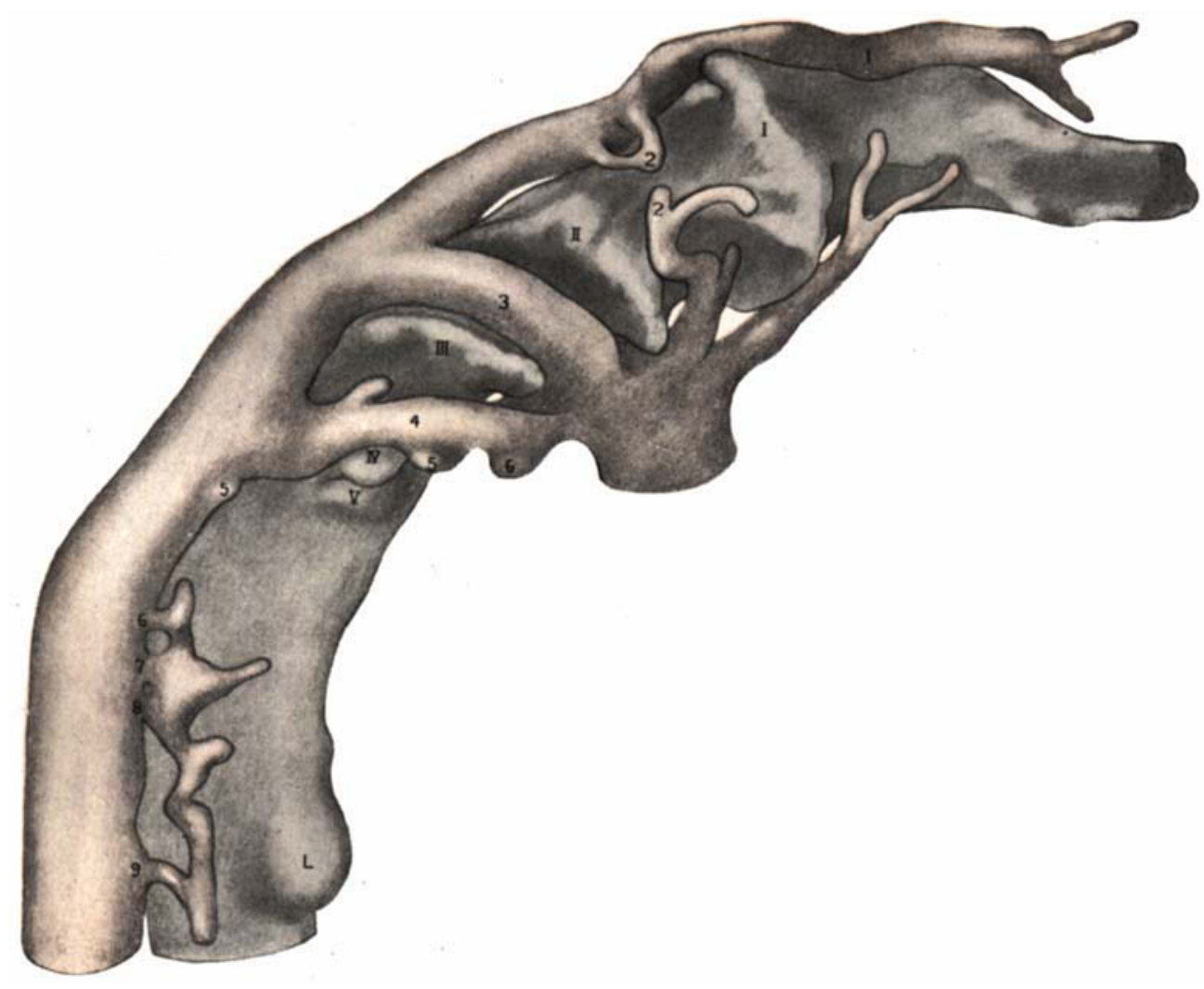


PLATE 2

Series 885 , C.U.E.C. $6-\mathrm{mm}$. cat, $\times 150$ 


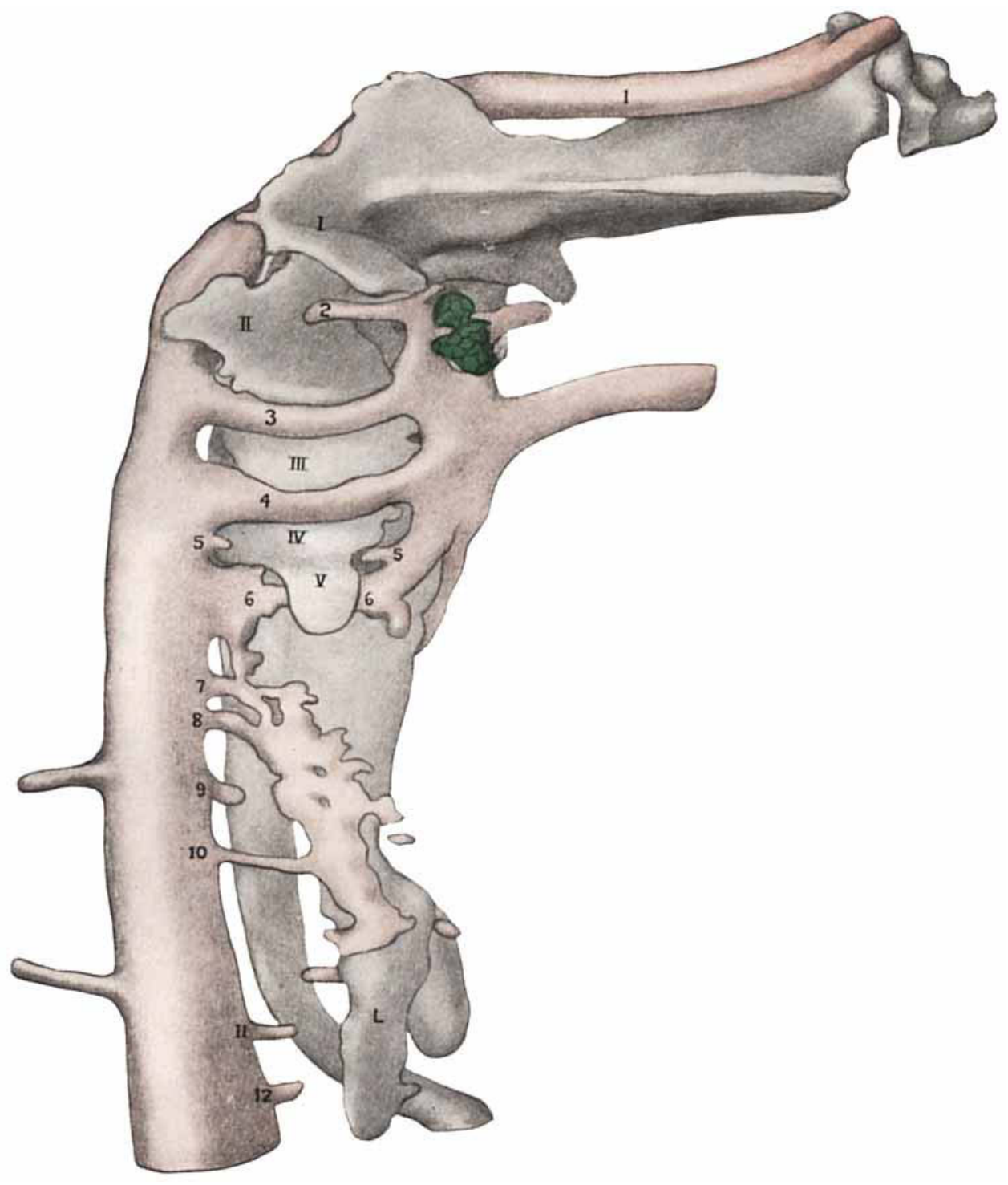


PLATE 3

Series 771, C.U.E.C. 4-mm. cat, $\times 150$ 


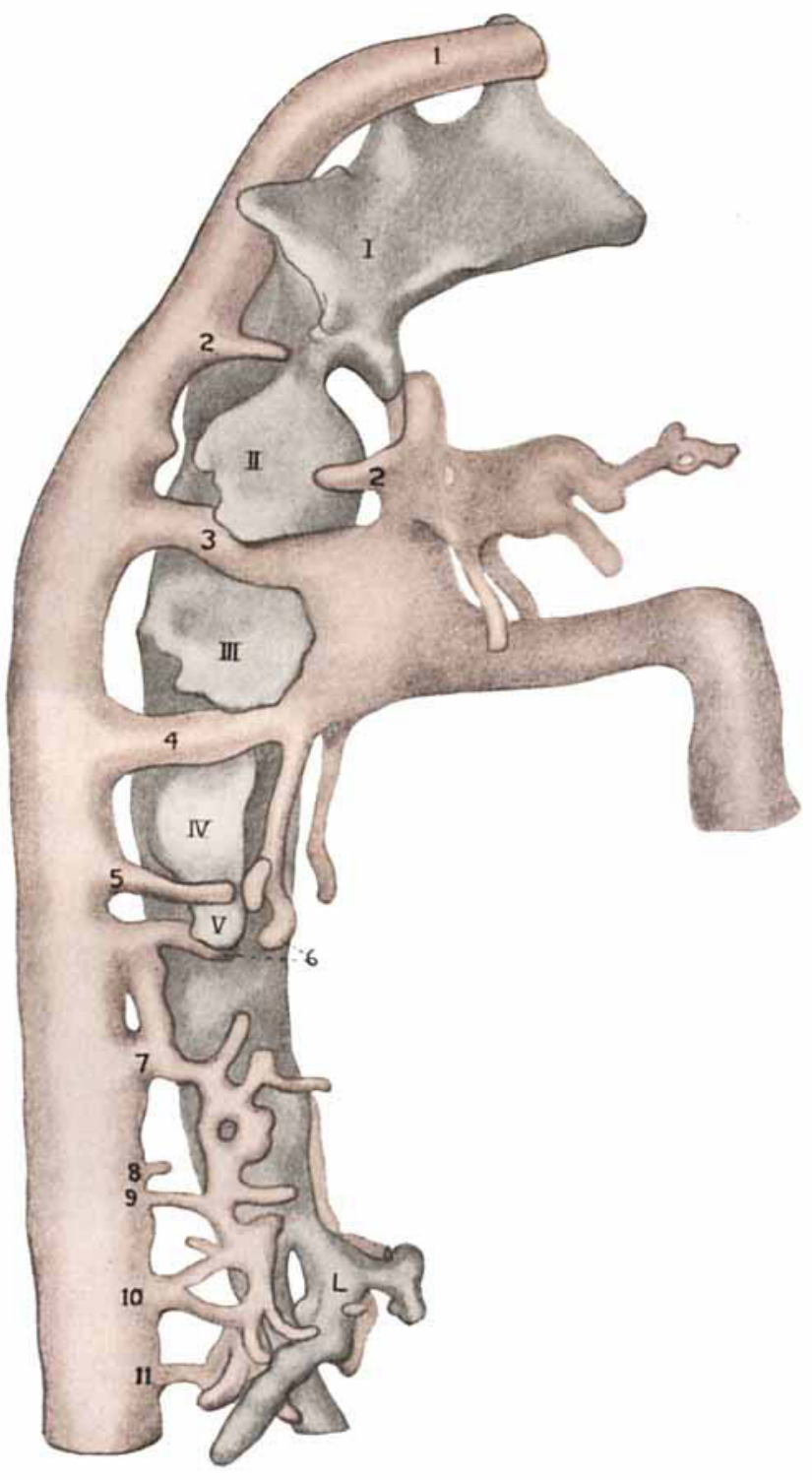


PIATF 4

Series 773 , C.U.E.C. 4-mm. cat, $\times 150$. Right side of model 


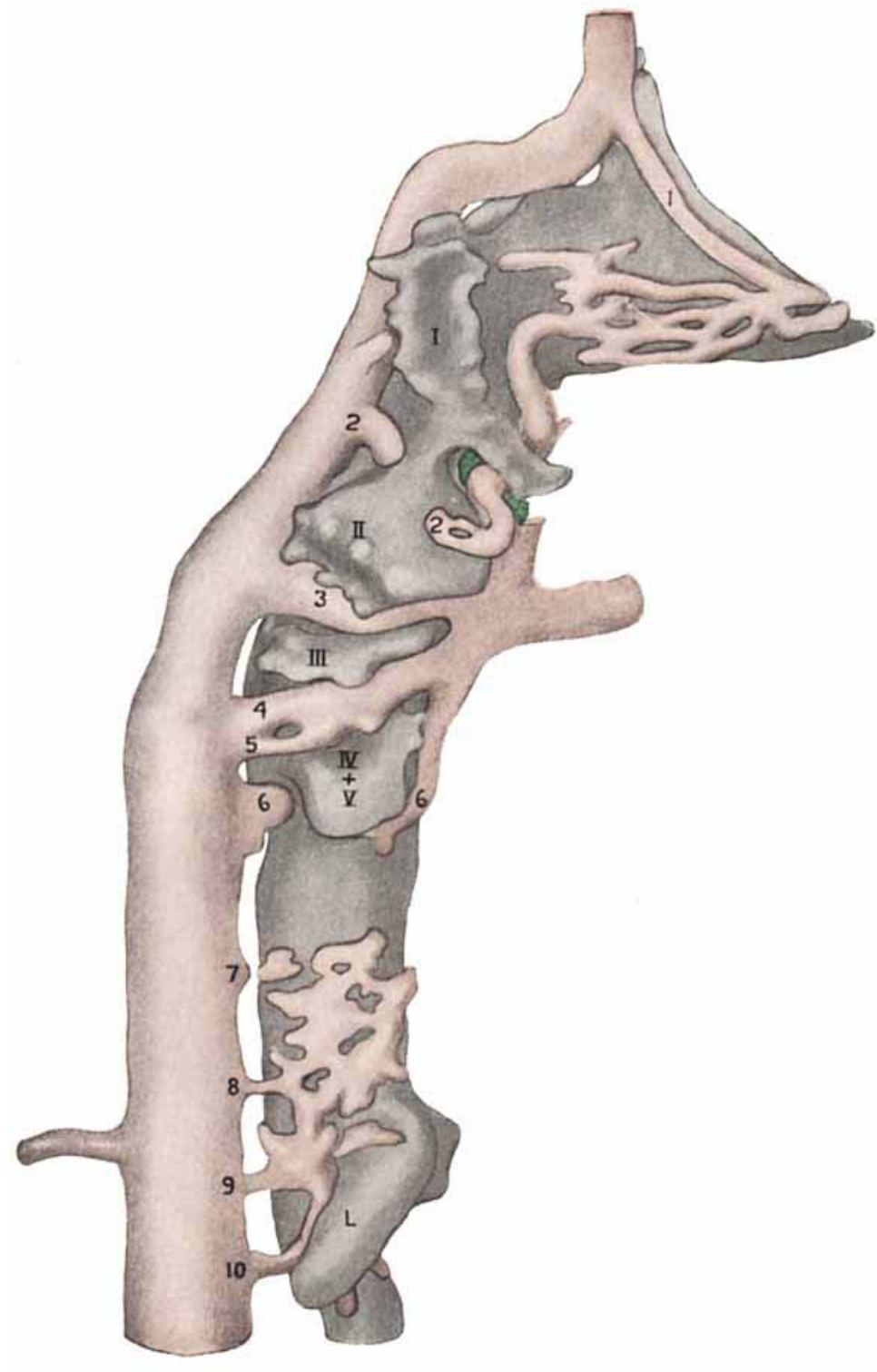

199

THT ANATOMICAL RECORD, YOL. 17 , NO. 4 
PLATE :)

Series 773, C.L.E.C. t-mm. cat, $\times$ 150. Left side of model 


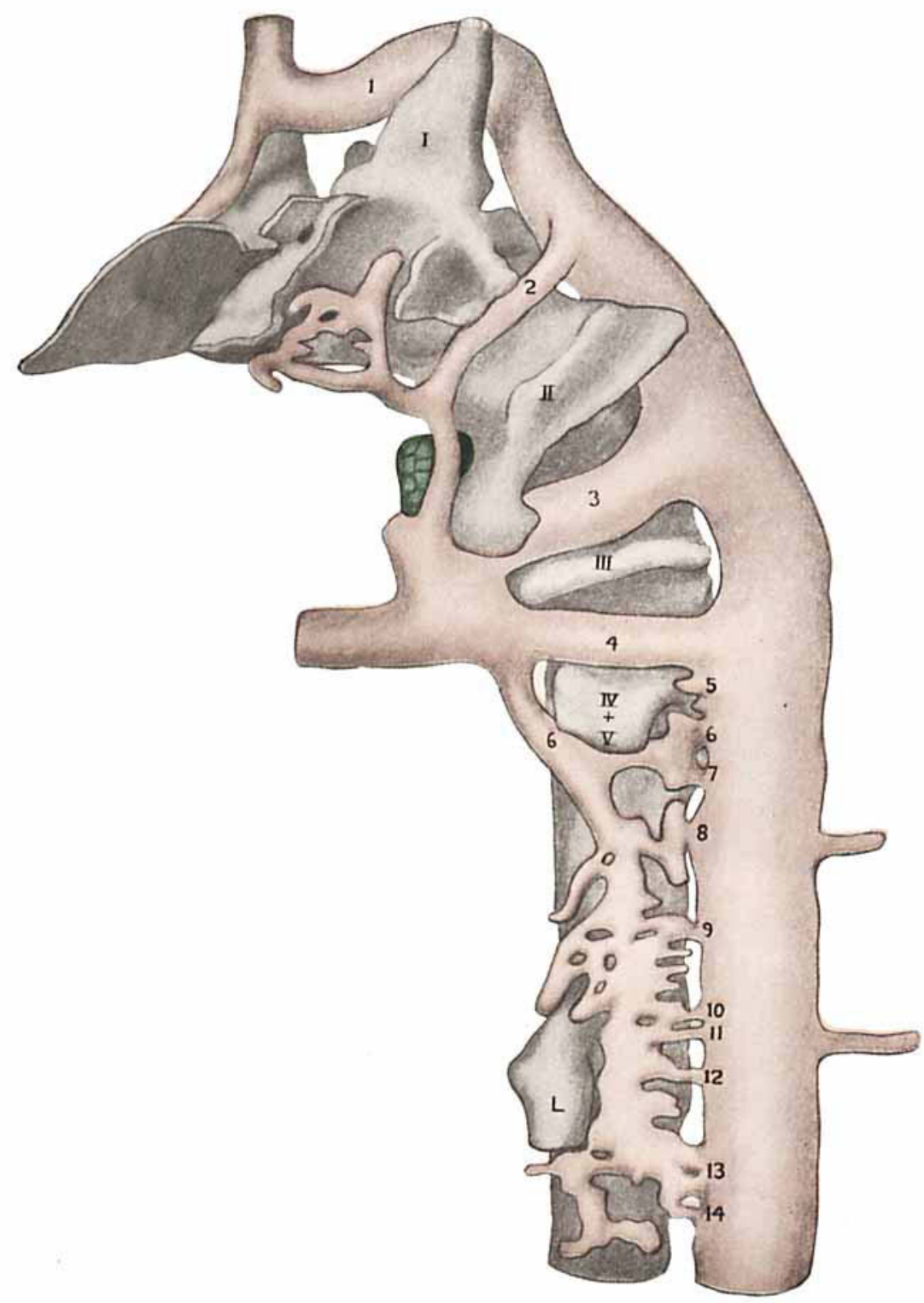

